\title{
Corrosion Behavior of A356-10 Vol.\% SiC Composites Cast by Gravity and Squeeze Casting in $\mathrm{H}_{2} \mathrm{SO}_{4}$ Solutions
}

\author{
A. Fattah-alhosseini, ${ }^{1}$ M. Ranjbaran, ${ }^{2}$ and S. Vajdi Vahid ${ }^{2}$ \\ ${ }^{1}$ Department of Materials Engineering, Faculty of Engineering, Bu-Ali Sina University, Hamedan 65178-38695, Iran \\ ${ }^{2}$ Department of Materials Engineering, Faculty of Mechanical Engineering, Shahid Rajaee Teacher Training University, \\ Tehran 16785-136, Iran
}

Correspondence should be addressed to A. Fattah-alhosseini; arash.fattah@gmail.com

Received 17 February 2014; Revised 18 June 2014; Accepted 18 June 2014; Published 8 July 2014

Academic Editor: Flavio Deflorian

Copyright (C) 2014 A. Fattah-alhosseini et al. This is an open access article distributed under the Creative Commons Attribution License, which permits unrestricted use, distribution, and reproduction in any medium, provided the original work is properly cited.

\begin{abstract}
Corrosion behavior of $\mathrm{A} 356-10 \mathrm{vol} . \% \mathrm{SiC}$ composites cast by gravity and squeeze casting is evaluated. For this purpose, prepared samples were immersed in $\mathrm{H}_{2} \mathrm{SO}_{4}$ solution for $2 \mathrm{hrs}$. at open circuit potential. Tafel polarization and electrochemical impedance spectroscopy (EIS) were carried out to study the corrosion resistance of composites. The results showed that corrosion resistance of composites cast by squeeze casting is higher than that of the gravity cast composites. The micrographs of scanning electron microscope (SEM) clearly showed the squeeze casting composites exhibit a good dispersion/matrix interface when compared with composites produced by gravity casting.
\end{abstract}

\section{Introduction}

A356 aluminium alloy is a casting alloy consisting of aluminium, silicon, and magnesium. It is distinguished by good mechanical characteristics and high ductility, as well as excellent casting characteristics and high corrosion resistance. The alloy is widely used in various types of machineries, aircraft, and defense industries. The alloy is particularly used in automotive industries in order to replace steel components [1].

A356 aluminium alloy is also used as the basis for obtaining composites with ceramic reinforcing particles and fibers such as $\mathrm{SiC}, \mathrm{Al}_{2} \mathrm{O}_{3}$, and $\mathrm{ZrO}_{2}$. [2-4]. These metal matrix composites (MMCs) have found widespread use in many engineering applications because of their good performance, such as high strength, high hardness, excellent wear resistance, low-heat expansion coefficient, and competitive cost [5-11].

One of the main disadvantages of particulate reinforced MMCs is the influence of reinforcement on the corrosion resistance. This is of particular importance in aluminium alloy based composites where corrosion resistance is imparted by a protective oxide film. The addition of a reinforcing phase can lead to discontinuities or flaws in the protective film, increasing the sites for corrosion initiation and rendering the composite liable to severe corrosion attack [12]. The study on the corrosion behavior of MMCs in different aggressive environments has continued to attract considerable attention because of the several important applications of these materials. These composites frequently come in contact with acids or bases during processes such as cleaning, pickling, and descaling. It is known that aluminium and its alloys exhibit high corrosion rate in solutions containing aggressive anions or in highly alkaline solutions [13-15].

Therefore, studying the corrosion behavior of aluminium alloys and their composites in the acidic medium is of prime importance. One of the major drawbacks of gravity casting is the formation of defects such as porosity, which will be the potential crack initiators during service operation of the as-cast components. The aim of this study is to compensate for the shortcomings. Squeeze casting has greater potential to create less defective cast components [6]. Therefore, this paper deals with the corrosion behavior of A356-10 vol.\% SiC 
TABLE 1: Chemical compositions of A356 aluminium alloy.

\begin{tabular}{lcccccccr}
\hline Elements & $\mathrm{Si}$ & $\mathrm{Mg}$ & $\mathrm{Fe}$ & $\mathrm{Cu}$ & $\mathrm{Mn}$ & $\mathrm{Zn}$ & $\mathrm{Ti}$ & $\mathrm{Al}$ \\
\hline $\mathrm{A} 356 / \mathrm{wt} \%$ & 7.5 & 0.33 & 0.40 & 0.16 & 0.09 & 0.32 & 0.04 & $\mathrm{Bal}$. \\
\hline
\end{tabular}

TABLE 2: The process parameters of gravity and squeeze casting.

\begin{tabular}{lcc}
\hline & $\begin{array}{c}\text { Gravity } \\
\text { casting }\end{array}$ & $\begin{array}{c}\text { Squeeze } \\
\text { casting }\end{array}$ \\
\hline Preheated temperature of mold $\left({ }^{\circ} \mathrm{C}\right)$ & $150-200$ & $150-200$ \\
Casting temperature $\left({ }^{\circ} \mathrm{C}\right)$ & 700 & 700 \\
Specific pressure of casting $(\mathrm{MPa})$ & - & 100 \\
Velocity of filling mold $(\mathrm{mm} / \mathrm{s})$ & 10 & 10 \\
Pressure permanent time $(\mathrm{s})$ & - & $10-15$ \\
The beginning time of pressing $(\mathrm{s})$ & - & $5-8$ \\
\hline
\end{tabular}

composites cast by gravity and squeeze casting in $\mathrm{H}_{2} \mathrm{SO}_{4}$ solutions.

\section{Experimental Procedures}

2.1. Producing of the Composites. The chemical composition of $\mathrm{A} 356 \mathrm{Al}$ alloy is given in Table 1 . In order to prepare the composites, the alloy was first melted and raised to $700^{\circ} \mathrm{C}$ in an electric furnace under controlled Argon atmosphere. The melt was maintained at this temperature for $2 \mathrm{~min}$. and $\mathrm{SiC}$ particles, with $99.9 \%$ purity and $50 \mu \mathrm{m}$ in size, were added while being stirred at $500 \mathrm{rpm}$. The schematic experimental set-up is shown in Figure 1.

To evaluate and compare the effect of casting technique on microstructure and corrosion behavior of composites, gravity and squeeze casting were carried out separately. The parameters of the gravity and squeeze casting are shown in Table 2. Also, schematic presentation of squeeze casting is shown in Figure 2.

Cubic test samples were cut from cast rods and mechanically polished with abrading wet emery paper up to 2000 grit size on all sides. The samples were then embedded in cold curing epoxy resin. Prior to all measurements, working electrodes were degreased with acetone, rinsed with distilled water, and dried with stream of air.

2.2. Medium. Aerated acidic solutions with three different concentrations were used. The compositions were $0.05,0.10$, and $0.50 \mathrm{M} \mathrm{H}_{2} \mathrm{SO}_{4}$, respectively. All solutions were made from analytical grade of $97 \% \mathrm{H}_{2} \mathrm{SO}_{4}$ and distilled water, and the tests were carried out at $25 \pm 1^{\circ} \mathrm{C}$.

2.3. Electrochemical Measurements. All electrochemical measurements were performed in a conventional three-electrode cell under aerated conditions. The counter electrode was a Pt plate, and all potentials were measured against $\mathrm{Ag} / \mathrm{AgCl}$ in saturated $\mathrm{KCl}$. Electrochemical measurements were obtained using $\mu$ autolab potentiostat/galvanostat controlled by a suitable computer. Prior to electrochemical measurements,

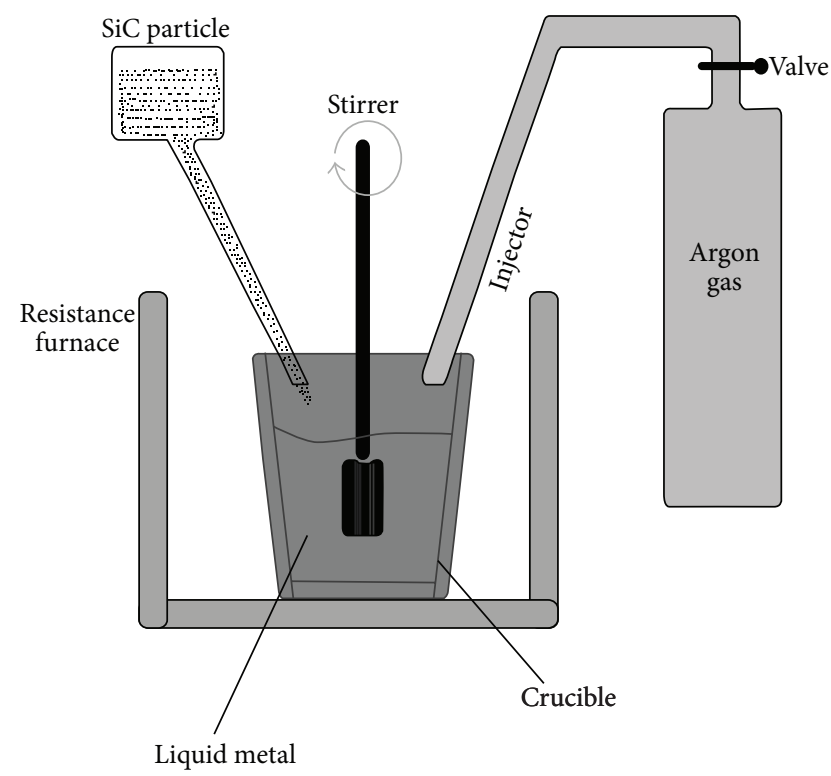

FIGURE 1: Schematic of the experimental set-up used in the production of the composites.

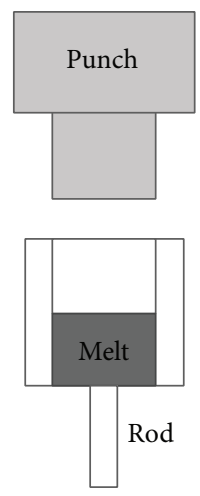

Step 1

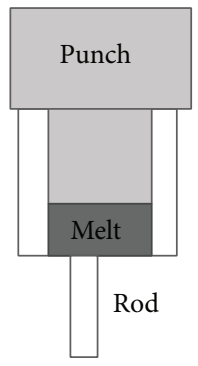

Step 2

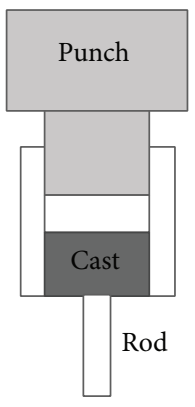

Step 3
FIgURE 2: The process schematic of the squeeze casting.

working electrodes were immersed in open circuit potential (OCP) for $2 \mathrm{~h}$ to form a steady-state passive film. The Tafel curves were recorded by polarizing the specimen to $-250 \mathrm{mV}$ cathodically and $+250 \mathrm{mV}$ anodically with respect to the OCP at a scan rate of $1 \mathrm{mV} \mathrm{s}^{-1}$. In EIS technique a small amplitude ac signal of $10 \mathrm{mV}$ peak-to-peak and frequency spectrum from $100 \mathrm{kHz}$ to $10 \mathrm{mHz}$ were impressed at the OCP and impedance data were analyzed using Nyquist plots. The polarization resistance was extracted from the diameter of the semicircle in the Nyquist plot. For EIS data modeling and curve-fitting method, NOVA software was used.

2.4. SEM. The surface morphology of the composite samples immersed in $\mathrm{H}_{2} \mathrm{SO}_{4}$ solutions was compared with that of the uncorroded ones by recording the SEM images of the surfaces 


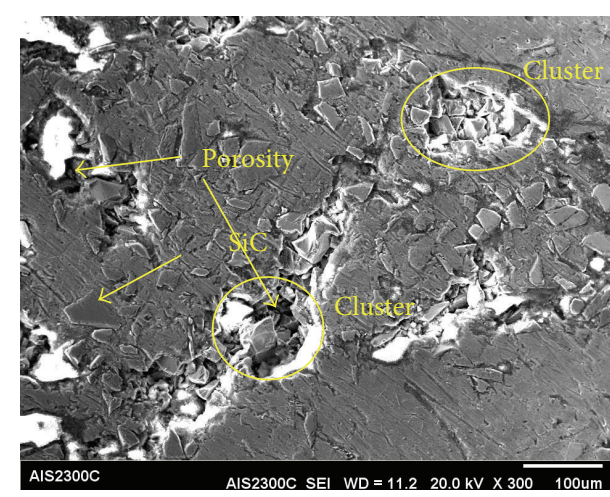

(a)

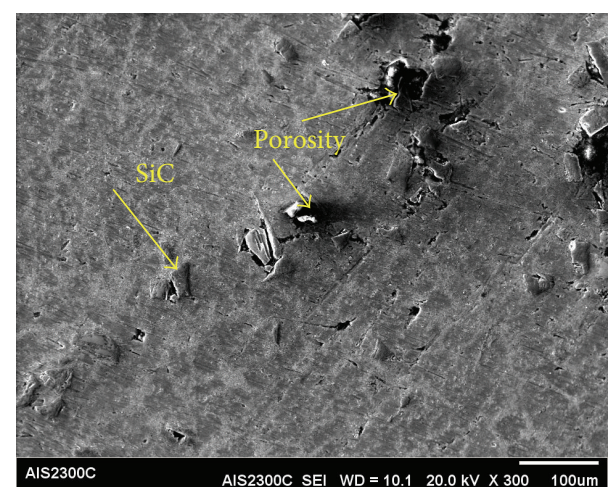

(b)

FIGURE 3: SEM micrograph showing surfaces of (a) gravity and (b) squeeze casting composites before immersion in $\mathrm{H}_{2} \mathrm{SO}_{4}$ solutions.

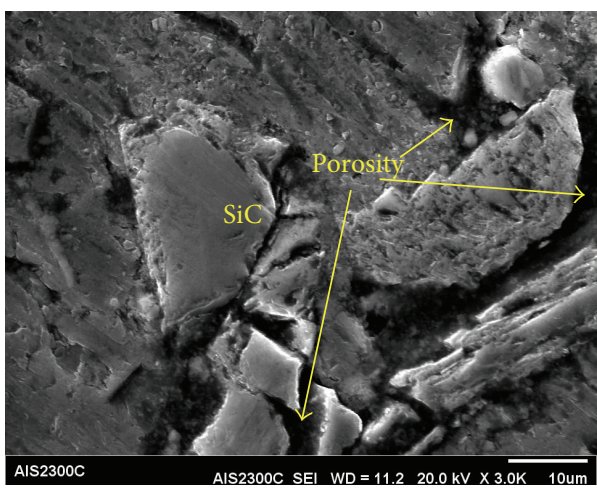

(a)

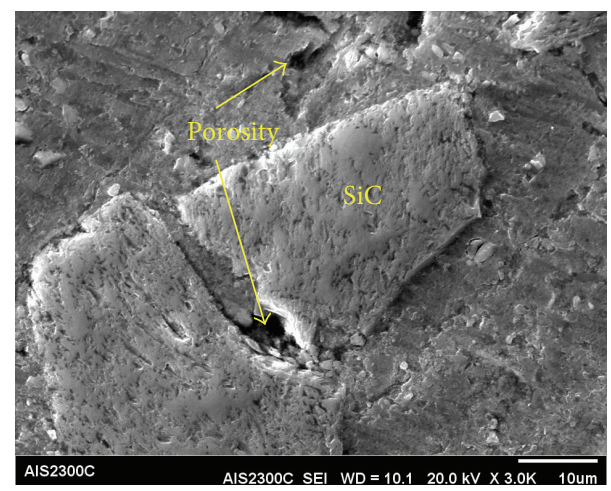

(b)

FIGURE 4: Relative high magnification of SEM micrograph showing surfaces of (a) gravity and (b) squeeze casting composites before immersion in $\mathrm{H}_{2} \mathrm{SO}_{4}$ solutions.

using SERON, AIS-2100 model analytical scanning electron microscope.

\section{Results and Discussion}

3.1. Microstructure. The SEM photographs of the surfaces of the gravity and squeeze casting composites are shown in Figures 3 and 4. As seen from Figures 3(a) and 4(a), SEM examination of the gravity casting composite demonstrated significant porosity throughout the specimen and frequent clustering of $\mathrm{SiC}$ particles around these pores. The porosity content of the gravity casting composite was evidently higher than that of squeeze casting composite (Figures 3(b) and 4(b)). During solidification process, the phases in composites shrink asynchronously due to the tremendous differences in heat properties. So looseness and shrinkage cavity will be brought about in the as-cast sample [6].

Generally, the gravity casting defects can be reduced by squeeze casting. The new casting technique means crystallizing, solidifying, and plastic deforming under high pressure, which combines the compulsory feeding and compaction. Before the punch clamps down, the melt has formed a chill shell. When the punch contacts the melt, the whole molten composite is enclosed in the die. Then the solidifying shell will deform and feed plastically $[6,17]$. Meanwhile the melt at the front of the solidifying region will be squeezed into the gaps due to shrinkage under high pressure (100 MPa).

3.2. Tafel Polarization Measurements. Figure 5 illustrates the Tafel polarization curves recorded for the gravity and squeeze casting composites in $\mathrm{H}_{2} \mathrm{SO}_{4}$ solutions with different concentrations. The electrochemical parameters such as corrosion potential $\left(E_{\text {corr }}\right)$ and corrosion current density $\left(i_{\text {corr }}\right)$ at different concentrations of $\mathrm{H}_{2} \mathrm{SO}_{4}$ medium for both the composites are summarized in Table 3 . It is seen from the data that the corrosion current density $\left(i_{\text {corr }}\right)$ increases with the increase in $\mathrm{H}_{2} \mathrm{SO}_{4}$ concentration for both composites. It is also evident from Figure 4 and the data in Table 3 that the $E_{\text {corr }}$ values are shifted in the negative potential direction with the increase in the concentration of $\mathrm{H}_{2} \mathrm{SO}_{4}$ (except $0.05 \mathrm{M}$ ). The trend is similar for both composites. The decrease in corrosion potential $\left(E_{\text {corr }}\right)$ value indicates loss of passivity due to thinning the primary oxide layer by chemical dissolution.

Acidic corrosion of aluminium involves the dissolution of aluminium and formation of aluminium hydroxide as partial anodic reactions together with the oxygen/water reduction 


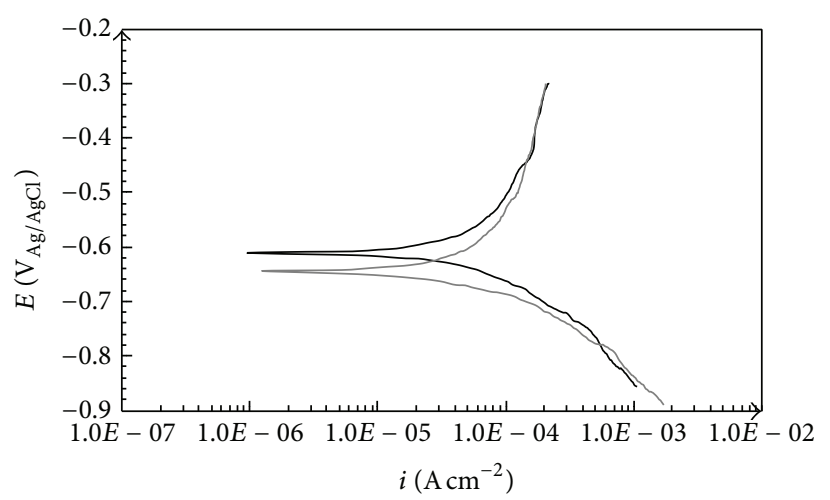

(a)

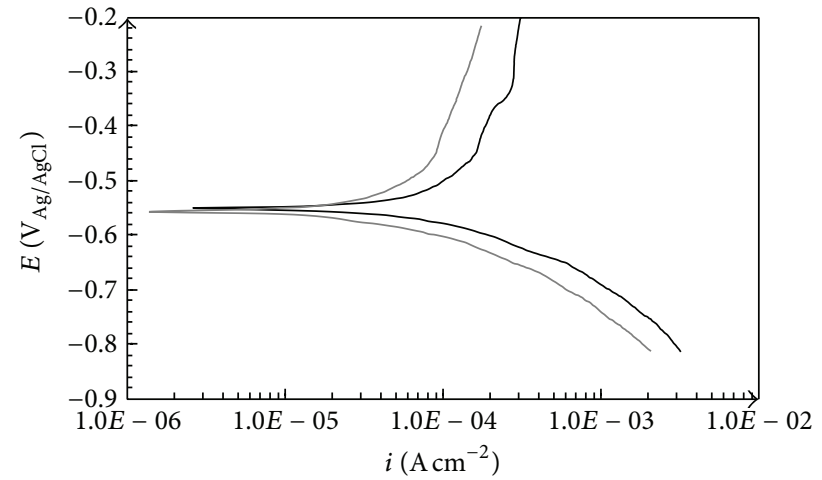

(b)

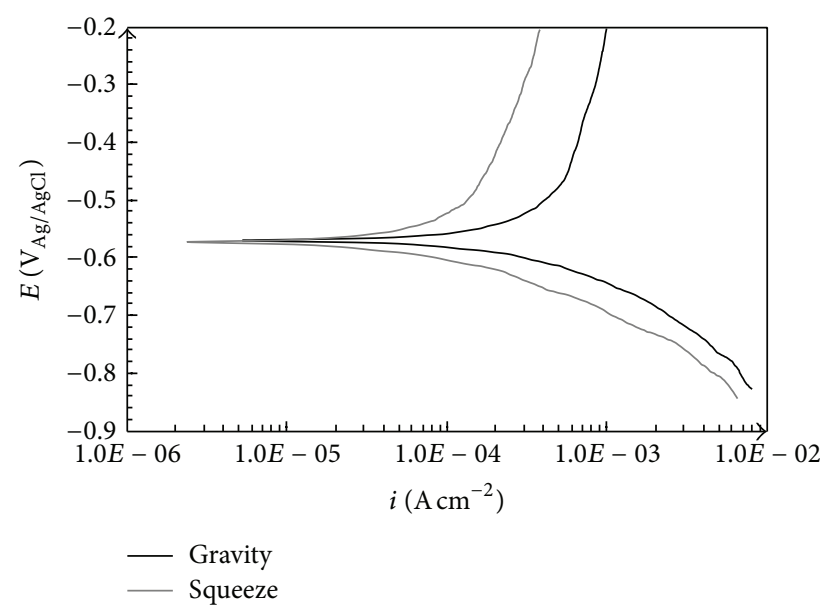

(c)

Figure 5: Tafel plots of A356-10 vol.\% $\mathrm{SiC}$ composites cast by gravity and squeeze casting in (a) $0.05 \mathrm{M}$, (b) $0.10 \mathrm{M}$, and (c) $0.50 \mathrm{M} \mathrm{H}_{2} \mathrm{SO}_{4}$ solutions.

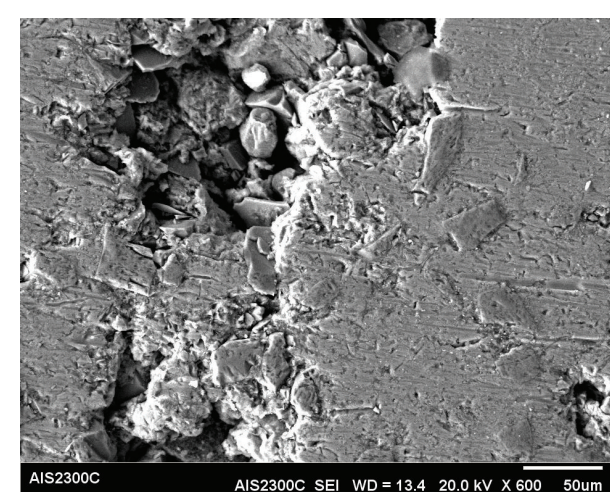

(a)

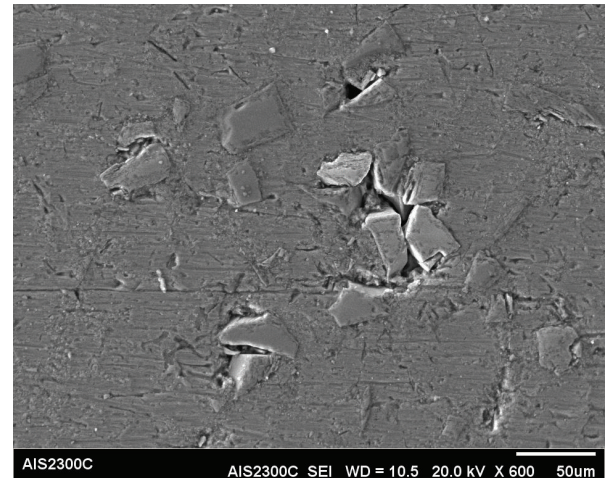

(b)

FIGURE 6: SEM micrograph showing surfaces of (a) gravity and (b) squeeze casting composites after immersion in $0.10 \mathrm{M} \mathrm{H}_{2} \mathrm{SO}_{4}$ solution for $2 \mathrm{~h}$.

and formation of hydrogen bubbles as partial cathodic reactions, according to the following equations [18]:

$$
\begin{gathered}
\mathrm{Al}=\mathrm{Al}^{3+}+3 \overline{\mathrm{e}} \\
\mathrm{Al}^{3+}+3 \mathrm{H}_{2} \mathrm{O}=\mathrm{Al}(\mathrm{OH})_{3}+3 \overline{\mathrm{e}} \\
2 \mathrm{H}^{+}+2 \overline{\mathrm{e}}=\mathrm{H}_{2}
\end{gathered}
$$

$$
\mathrm{O}_{2}+2 \mathrm{H}_{2} \mathrm{O}+4 \overline{\mathrm{e}}=4 \mathrm{OH}^{-}
$$

Also film dissolution can be treated as a purely chemical reaction. Therefore, when aluminum is immersed in aqueous solutions, formation of the hydroxide film through incorporation and diffusion of ions into the film is occurring. However, at the same time, dissolution at the film/solution 


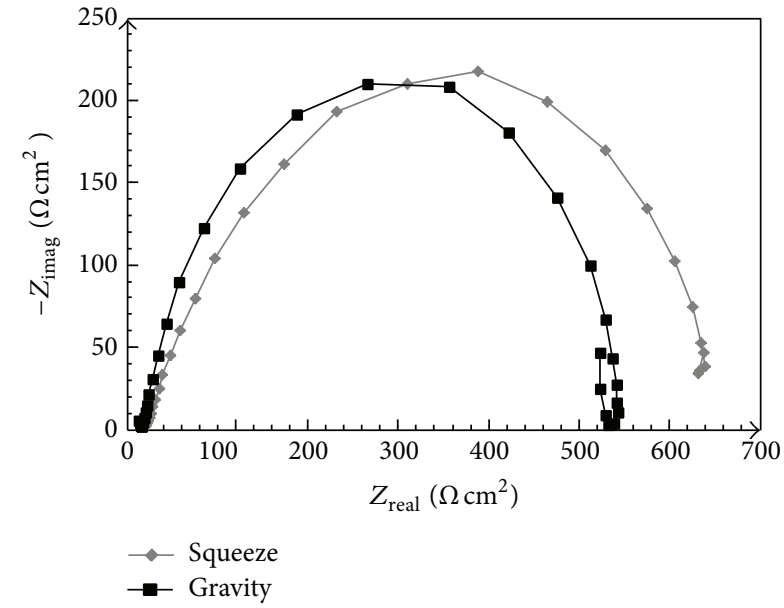

(a)

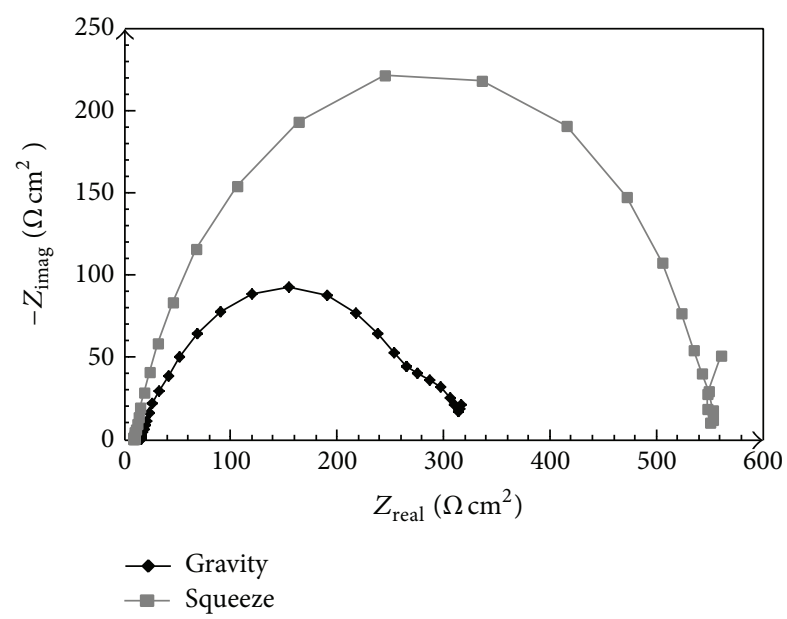

(b)

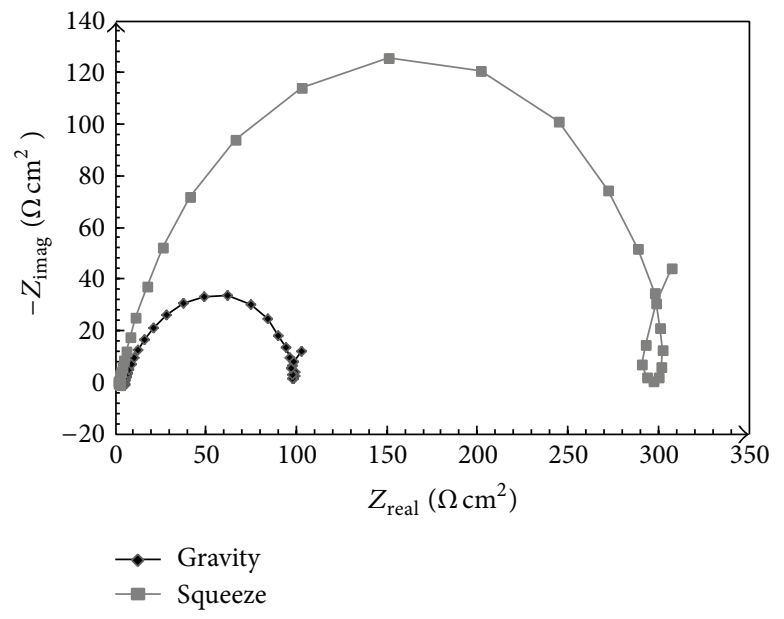

(c)

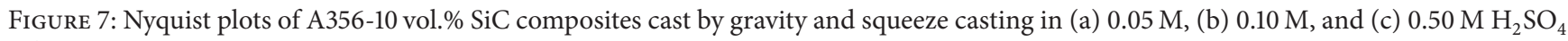
solutions.

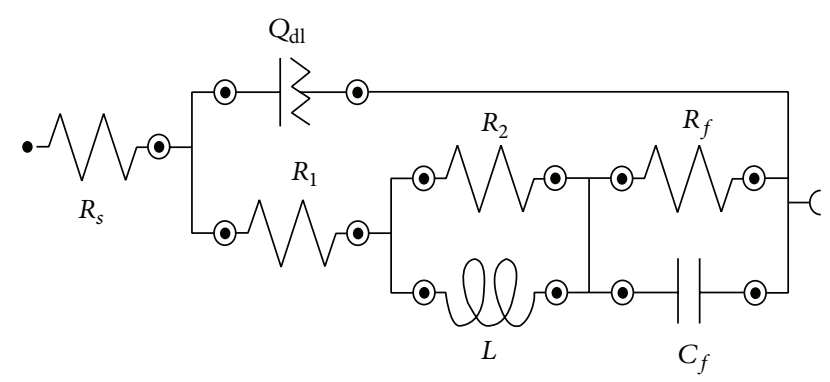

FIGURE 8: The equivalent circuit used to model the experimental EIS data [16].

interface is also happening. In other words, the formation and the dissolution of the film are in dynamic equilibrium. Furthermore, anions present in the solution can participate in the dissolution reaction through the formation of transitory complexes [18].
TABLE 3: Results of Tafel polarization studies for the corrosion behavior of A356-10 vol.\% $\mathrm{SiC}$ composites cast by gravity and squeeze casting in $\mathrm{H}_{2} \mathrm{SO}_{4}$ solutions.

\begin{tabular}{lccc}
\hline $\begin{array}{l}\mathrm{H}_{2} \mathrm{SO}_{4} \\
\text { solutions }\end{array}$ & $\begin{array}{c}\text { Casting } \\
\text { type }\end{array}$ & $\begin{array}{c}E_{\text {corr }} \\
(\mathrm{V})\end{array}$ & $\begin{array}{c}i_{\text {corr }} \\
\left(\mathrm{A} \mathrm{cm}^{-2}\right)\end{array}$ \\
\hline \multirow{2}{*}{$0.05 \mathrm{M}$} & Gravity & -0.615 & $4.5 \times 10^{-5}$ \\
& Squeeze & -0.645 & $2.1 \times 10^{-5}$ \\
\hline \multirow{2}{*}{$0.10 \mathrm{M}$} & Gravity & -0.550 & $7.1 \times 10^{-5}$ \\
& Squeeze & -0.560 & $2.8 \times 10^{-5}$ \\
\hline \multirow{2}{*}{$0.50 \mathrm{M}$} & Gravity & -0.565 & $1.2 \times 10^{-4}$ \\
& Squeeze & -0.570 & $3.9 \times 10^{-5}$ \\
\hline
\end{tabular}

The SEM micrographs of the surfaces for gravity and squeeze casting composites after immersion in $0.10 \mathrm{M} \mathrm{H}_{2} \mathrm{SO}_{4}$ solution for $2 \mathrm{~h}$ are given in Figure 6. It is clear that the gravity casting composite appears to have undergone more corrosion than the squeeze casting composites. This can be 


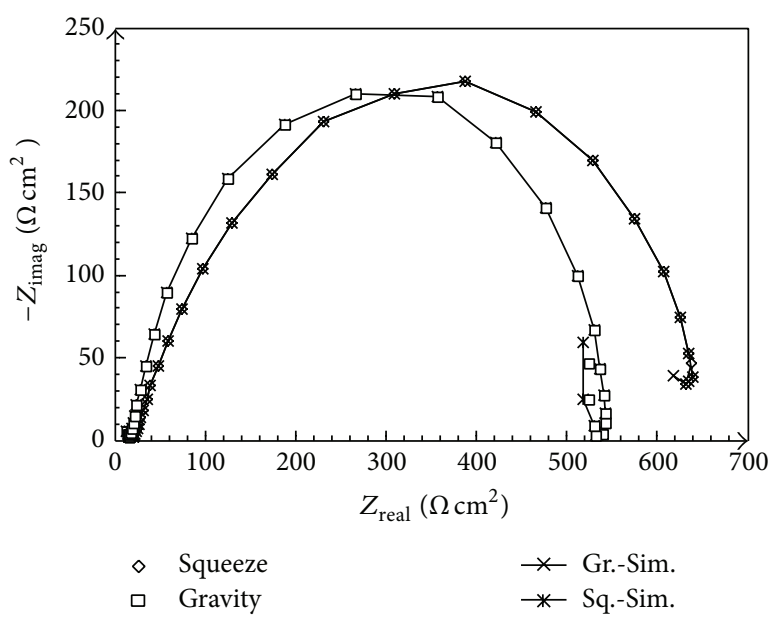

(a)

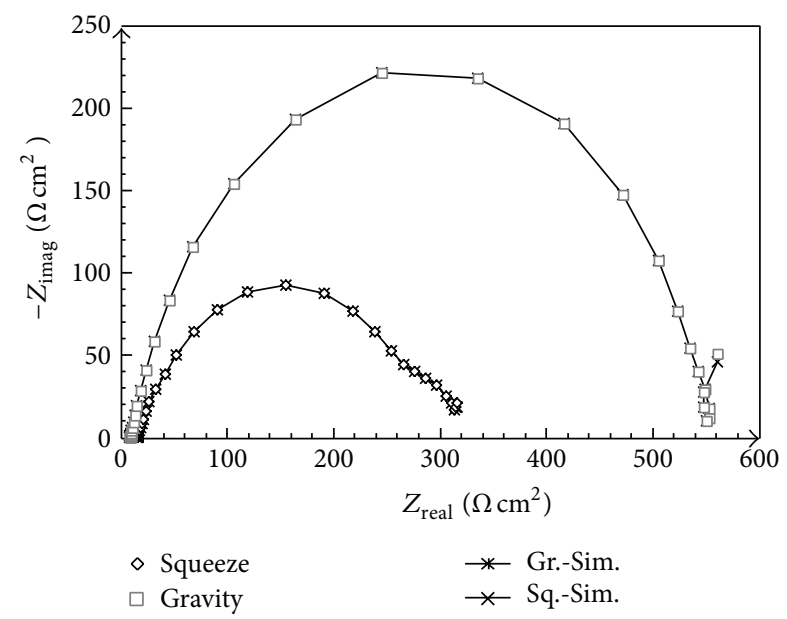

(b)

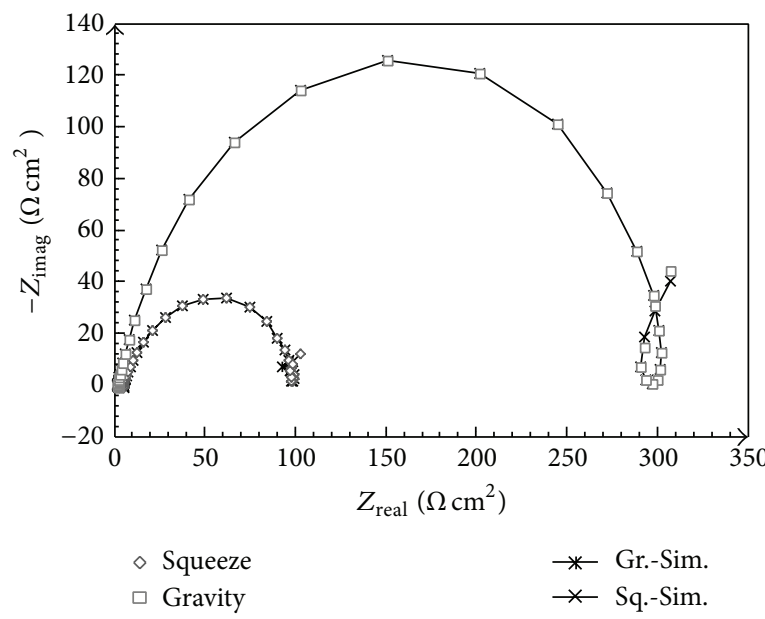

(c)

Figure 9: The fitting results of A356-10 vol.\% $\mathrm{SiC}$ composites cast by gravity and squeeze casting in (a) $0.05 \mathrm{M}$, (b) $0.10 \mathrm{M}$, and (c) $0.50 \mathrm{M}$ $\mathrm{H}_{2} \mathrm{SO}_{4}$ solutions using the equivalent circuit in Figure 8 .

attributed to the high porosity content produced by gravity casting (Figures 3(b) and 4(b)).

\subsection{EIS Measurements. Nyquist plots for the corrosion of the} gravity and squeeze casting composites in $\mathrm{H}_{2} \mathrm{SO}_{4}$ solutions of different concentrations are given in Figure 7. As can be seen from Figure 7, the impedance diagrams show semicircles, indicating that the corrosion process is mainly charge transfer controlled. The general shapes of the curves are identical for both composites in $\mathrm{H}_{2} \mathrm{SO}_{4}$ solutions of different concentrations, with a large capacitive loop at higher frequencies and a small inductive loop at intermediate frequencies, followed by a second capacitive loop at lower frequency values. Similar plots have been reported in the literature for the corrosion of aluminium alloys in acidic solutions [19].

The high frequency capacitive loop could be assigned to the charge transfer of the corrosion process and to the formation of oxide layer. The oxide film is considered to be a parallel circuit of a resistor due to the ionic conduction in the oxide film and a capacitor due to its dielectric properties.
According to Brett, the capacitive loop is corresponding to the interfacial reactions, particularly the reaction of aluminium oxidation at the metal/oxide/electrolyte interface. The process includes the formation of $\mathrm{Al}^{+}$ions at the metal/oxide interface and their migration through the oxide/solution interface where they are oxidized to $\mathrm{Al}^{3+}$. At the oxide/solution interface, $\mathrm{OH}^{-}$ions are also formed. The inductive loop at intermediate frequencies may be due to the relaxation process in the oxide layer, present on the metal surface by the adsorbed intermediate species as $\mathrm{OH}$-Ads. The second capacitive loop observed at low frequencies could be assigned to the metal dissolution [14].

The impedance data were analyzed using an equivalent circuit that tentatively models the physical processes occurring at the metal-electrolyte interface. The equivalent circuit depicted in Figure 8 [16] was used to simulate the measured impedance data on the A356-10 vol.\% $\mathrm{SiC}$ composites cast by gravity and squeeze casting in $\mathrm{H}_{2} \mathrm{SO}_{4}$ solutions.

It has been stated that $\mathrm{Al}$ dissolves into an alkaline solution through a stepwise addition of surface hydroxyl 


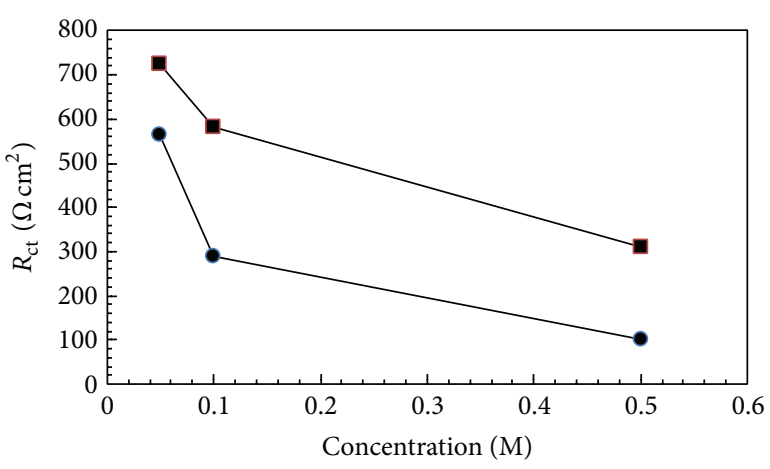

(a)

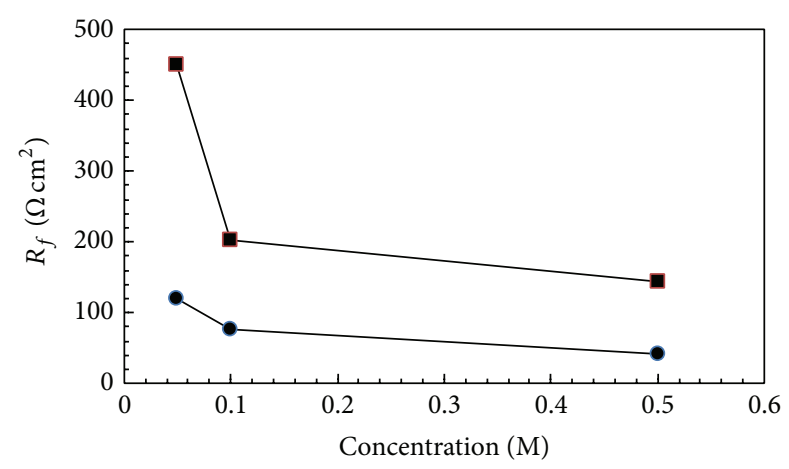

(b)

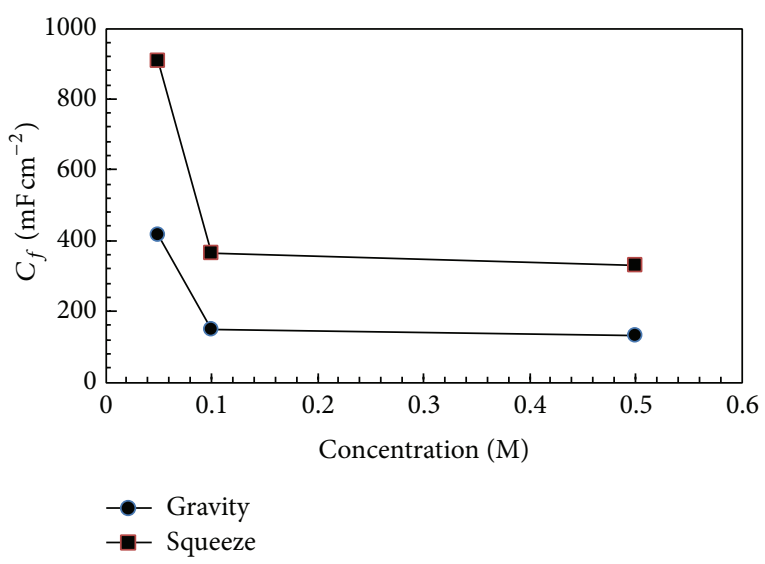

(c)

FIgURE 10: Variation of (a) $R_{\mathrm{ct}}$, (b) $R_{f}$, and (c) $C_{f}$ with concentration for A356-10 vol.\% $\mathrm{SiC}$ composites cast by gravity and squeeze casting in $\mathrm{H}_{2} \mathrm{SO}_{4}$ solutions.

species, culminating in the chemical dissolution of $\mathrm{Al}(\mathrm{OH})_{3}$ in the presence of surface oxide film. The equivalent circuit depicted in Figure 8 was utilized to describe the impedance spectra of A356-10 vol.\% $\mathrm{SiC}$ composites in $\mathrm{H}_{2} \mathrm{SO}_{4}$ solutions because the $\mathrm{Al}$ dissolution into an acidic solution (according to reaction 1 to 4 ) was similar to that of $\mathrm{Al}$ dissolution in an alkaline solution. This equivalent circuit has been reported as excellent, in order to model the corrosion behavior of $6061 / \mathrm{Al}-15$ vol.\% $\mathrm{SiC}$ composite in a sodium hydroxide solution [14].

This equivalent circuit is composed of a Faradaic impedance parallel to a double layer constant phase element,
$Q_{\mathrm{dl}}$. Faradaic impedance consists of $R_{\mathrm{ct}}\left(=R_{1}+R_{2}\right)$ indicating the charge transfer resistance at the metal/oxide film interface, $L$ resulting from the interruption of anodic dissolution of $\mathrm{Al}$ by the surface charge build-up, $R_{f}$ being the resistance against charge transport in the oxide film, and $C_{f}$ due to the dielectric properties of surface oxide film. The $R_{s}$ component in the circuit is a solution resistance with the value at a high frequency intercept on the real impedance axis [16]. This equivalent circuit was provided excellent fitting as shown in Figure 9.

The electrochemical parameters for the impedance spectra of A356-10 vol.\% SiC composites cast by gravity and squeeze casting as a function of the concentration are shown in Figure 10. As the concentration increases, charge transfer resistance, $R_{\mathrm{ct}}$, oxide film resistance, $R_{f}$, and oxide film capacitance, $C_{f}$, decrease for both the composites. Since the oxide film capacitance, $C_{f}$, due to the dielectric properties of oxide film, is correlated to the film thickness, $d$, and the dielectric constant, $\varepsilon$, of oxide film, it can be expressed as [20]

$$
C_{f}=\frac{\varepsilon \varepsilon_{0}}{d},
$$

where $\varepsilon=8.85 \times 10^{-12} \mathrm{~F}^{-1} \mathrm{~m}^{-1}$ is the permittivity of the vacuum; the reduction of oxide film capacitance indicates the increase in oxide film thickness. Since the decrease of the oxide film capacitance means the increase in the oxide film thickness in (5), it indicates that the oxide film resistance decreases in spite of an increase in its thickness.

\section{Conclusions}

Based on the systematic study of the corrosion behavior of A356-10 vol.\% SiC composites in different concentrations of $\mathrm{H}_{2} \mathrm{SO}_{4}$ solutions by electrochemical methods, the following conclusions are made.

(1) The SEM micrographs of the A356-10 vol.\% SiC composites showed that the squeeze casting composite exhibits a good dispersion/matrix interface when compared with the composite produced by gravity process.

(2) In squeeze casting, a limited amount of interfacial porosity was observed in the composite when compared to that of gravity casting technique.

(3) The Tafel polarization and EIS studies of the corrosion behavior of the A356-10 vol.\% $\mathrm{SiC}$ composites showed that the corrosion resistance of the composite cast by squeeze casting was higher than that of the composites cast by gravity in selected corrosion media.

(4) Also, the Tafel polarization and EIS studies revealed that the corrosion current densities of both composites increase with the increase in the concentration of $\mathrm{H}_{2} \mathrm{SO}_{4}$.

(5) EIS studies showed that as the concentration increases, the charge transfer resistance, oxide film resistance, and oxide film capacitance decrease for both composites. 


\section{Conflict of Interests}

The authors declare that there is no conflict of interests regarding the publication of this paper.

\section{References}

[1] A. Vencl, I. Bobic, S. Arostegui, B. Bobic, A. Marinković, and M. Babić, "Structural, mechanical and tribological properties of A356 aluminium alloy reinforced with $\mathrm{Al}_{2} \mathrm{O}_{3}, \mathrm{SiC}$ and $\mathrm{SiC}+$ graphite particles," Journal of Alloys and Compounds, vol. 506, no. 2, pp. 631-639, 2010.

[2] H. Ribes and M. Suéry, "Effect of particle oxidation on age hardening of AlSiMg/SiC composites," Scripta Metallurgica, vol. 23, no. 5, pp. 705-709, 1989.

[3] A. Daoud and W. Reif, "Influence of $\mathrm{Al}_{2} \mathrm{O}_{3}$ particulate on the aging response of A356 Al-based composites," Journal of Materials Processing Technology, vol. 123, no. 2, pp. 313-318, 2002.

[4] M. T. Abou El-Khair and A. Abdel Aal, "Erosion-corrosion and surface protection of $\mathrm{A} 356 \mathrm{Al} / \mathrm{ZrO}_{2}$ composites produced by vortex and squeeze casting," Materials Science and Engineering A, vol. 454-455, pp. 156-163, 2007.

[5] M. Cholewa, "Simulation of solidification process for composite micro-region with incomplete wetting of reinforcing particle," Journal of Materials Processing Technology, vol. 164-165, pp. 11811184, 2005.

[6] S. C. Tjong, G. S. Wang, and Y. W. Mai, "High cycle fatigue response of in-situ Al-based composites containing $\mathrm{TiB}_{2}$ and $\mathrm{Al}_{2} \mathrm{O}_{3}$ submicron particles," Composites Science and Technology, vol. 65, no. 10, pp. 1537-1546, 2005.

[7] G. R. Li, Y. T. Zhao, H. M. Wang, G. Chen, Q. X. Dai, and X. N. Cheng, "Fabrication and properties of in situ $\left(\mathrm{Al}_{3} \mathrm{Zr}+\mathrm{Al}_{2} \mathrm{O}_{3}\right)$ p/A356 composites cast by permanent mould and squeeze casting," Journal of Alloys and Compounds, vol. 471, no. 1-2, pp. 530-535, 2009.

[8] P. Yu, Z. Mei, and S. C. Tjong, "Structure, thermal and mechanical properties of in situ Al-based metal matrix composite reinforced with $\mathrm{Al}_{2} \mathrm{O}_{3}$ and TiC submicron particles," Materials Chemistry and Physics, vol. 93, no. 1, pp. 109-116, 2005.

[9] D. Roy, S. Ghosh, A. Basumallick, and B. Basu, "Preparation of Fe-aluminide reinforced in situ metal matrix composites by reactive hot pressing," Materials Science and Engineering A, vol. 415, no. 1-2, pp. 202-206, 2006.

[10] S. Zhiqiang, Z. Di, and L. Guobin, "Evaluation of dry sliding wear behavior of silicon particles reinforced aluminum matrix composites," Materials and Design, vol. 26, no. 5, pp. 454-458, 2005.

[11] M. Kök, "Abrasive wear of $\mathrm{Al}_{2} \mathrm{O}_{3}$ particle reinforced 2024 aluminium alloy composites fabricated by vortex method," Composites A, vol. 37, no. 3, pp. 457-464, 2006.

[12] A. J. Trowsdale, B. Noble, S. J. Harris, I. S. R. Gibbins, G. E. Thompson, and G. C. Wood, "The influence of silicon carbide reinforcement on the pitting behaviour of aluminium," Corrosion Science, vol. 38, no. 2, pp. 177-191, 1996.

[13] E. E. Oguzie, "Corrosion inhibition of aluminium in acidic and alkaline media by Sansevieria trifasciata extract," Corrosion Science, vol. 49, no. 3, pp. 1527-1539, 2007.

[14] P. D. Reena Kumari, J. Nayak, and A. Nityananda Shetty, "Corrosion behavior of 6061/Al-15 vol. pct. $\mathrm{SiC}_{(p)}$ composite and the base alloy in sodium hydroxide solution," Arabian Journal of Chemistry, 2012.
[15] G. M. Pinto, J. Nayak, and A. N. Shetty, "Corrosion behaviour of $6061 \mathrm{Al}-15 \mathrm{vol}$. Pct. SiC composite and its base alloy in a mixture of 1:1 Hydrochloric and sulphuric acid medium," International Journal of Electrochemical Science, vol. 4, no. 10, pp. 1452-1468, 2009.

[16] K.-K. Lee and K.-B. Kim, "Electrochemical impedance characteristics of pure $\mathrm{Al}$ and $\mathrm{Al}-\mathrm{Sn}$ alloys in $\mathrm{NaOH}$ solution," Corrosion Science, vol. 43, no. 3, pp. 561-575, 2001.

[17] K. M. Amin and N. A. Mufti, "Investigating cooling curve profile and microstructure of a squeeze cast $\mathrm{Al}-4 \% \mathrm{Cu}$ alloy," Journal of Materials Processing Technology, vol. 212, no. 8, pp. 1631-1639, 2012.

[18] D. Mercier, M. Herinx, and M.-G. Barthés-Labrousse, "Influence of 1,2-diaminoethane on the mechanism of aluminium corrosion in sulphuric acid solutions," Corrosion Science, vol. 52, no. 10, pp. 3405-3412, 2010.

[19] R. Rosliza, W. B. Wan Nik, and H. B. Senin, "The effect of inhibitor on the corrosion of aluminum alloys in acidic solutions," Materials Chemistry and Physics, vol. 107, no. 2-3, pp. 281-288, 2008.

[20] J. Bessone, C. Mayer, K. Jüttner, and W. J. Lorenz, "ACimpedance measurements on aluminium barrier type oxide films," Electrochimica Acta, vol. 28, no. 2, pp. 171-175, 1983. 

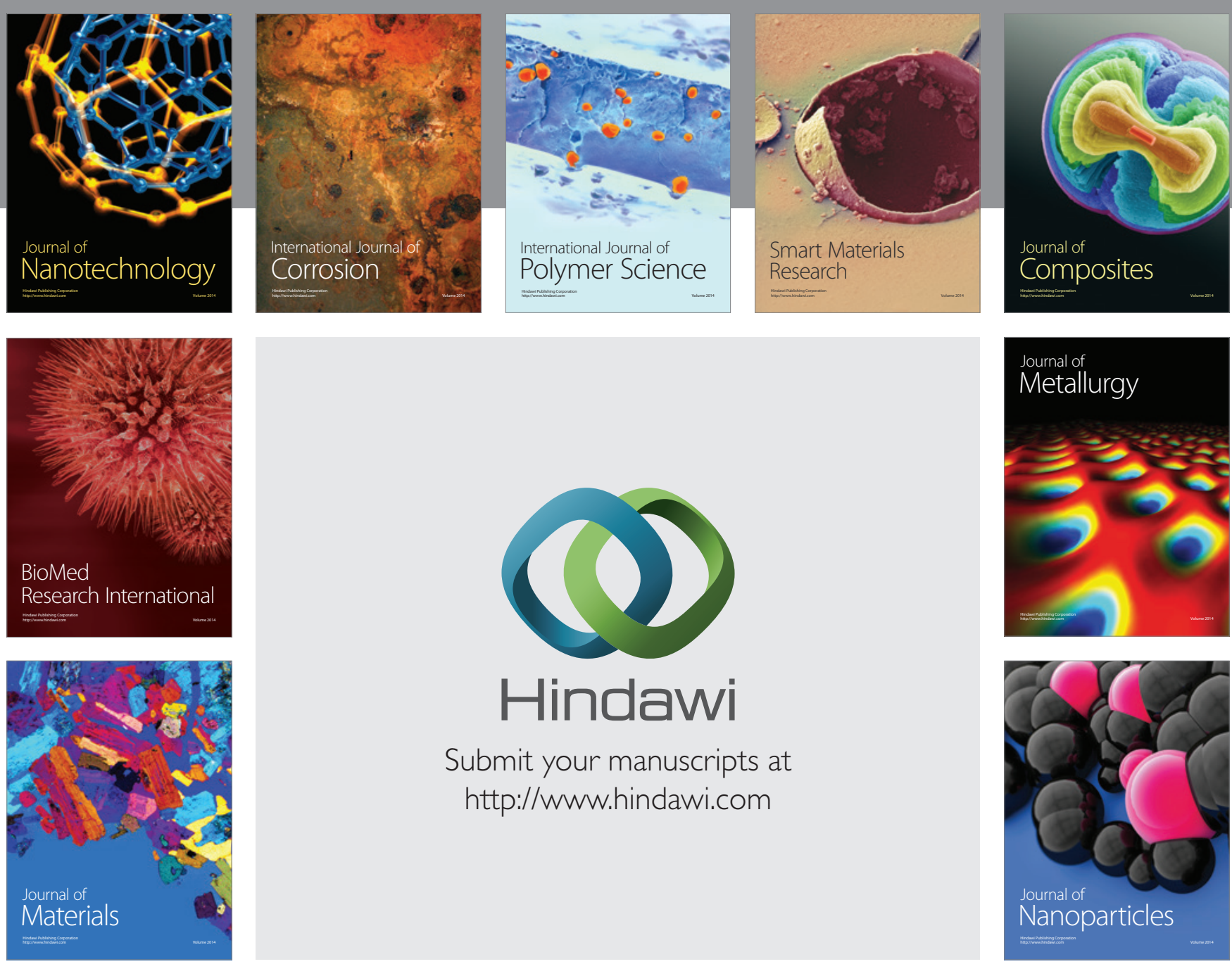

Submit your manuscripts at http://www.hindawi.com
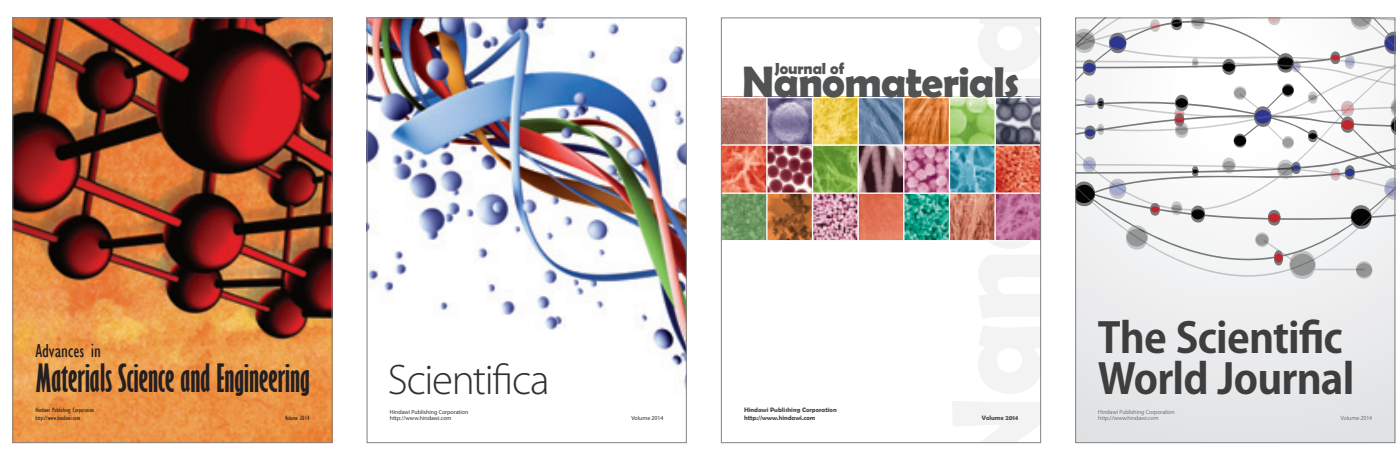

\section{The Scientific World Journal}
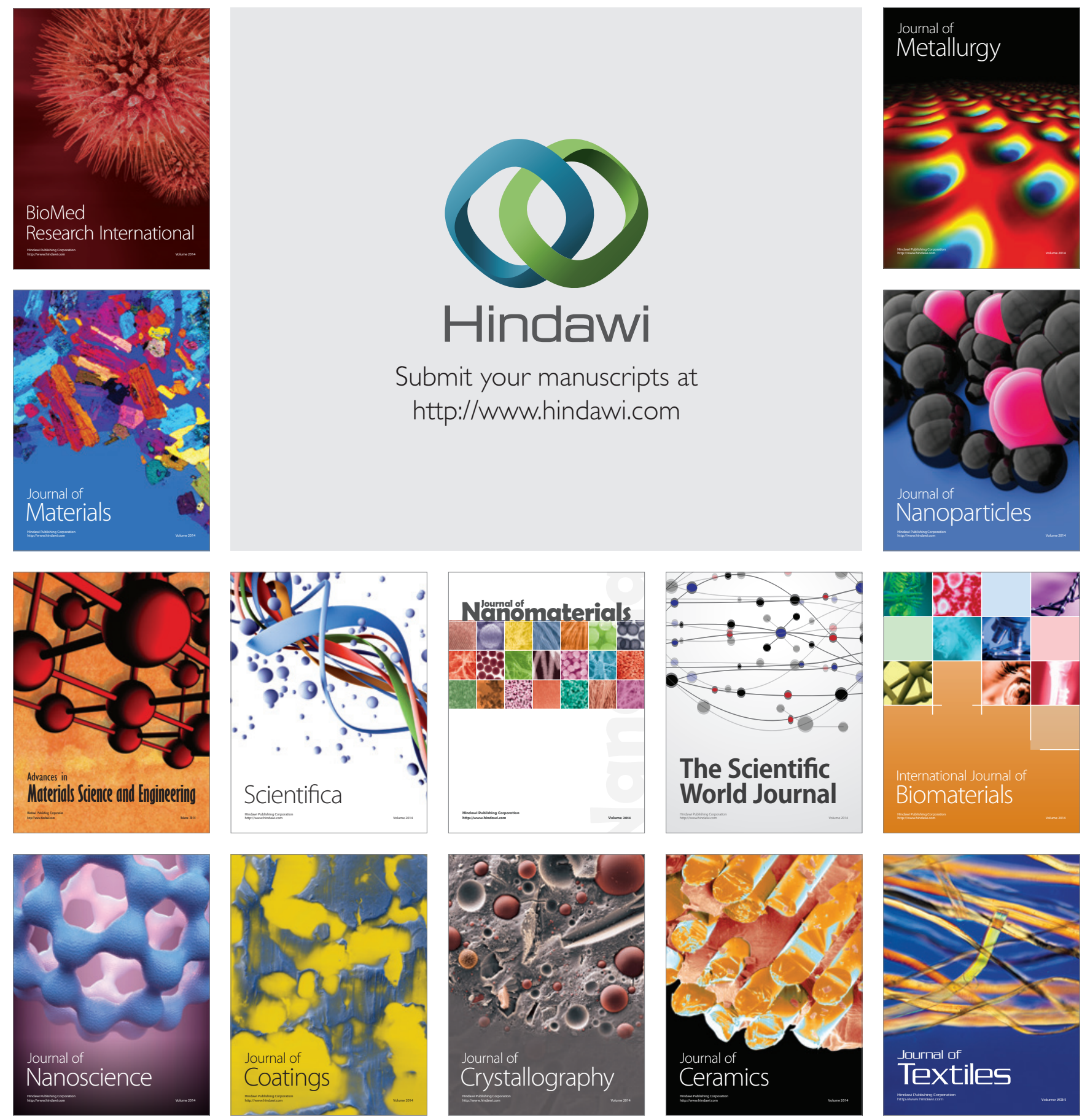